may have more than one initiating, perpetuating mechanism that we are sorely in need of more testable theories such as the one Dr Van Buskirk proposes. Future theories should integrate the vast amount of structural and functional knowledge obtained from laboratories, both within and outside of the profession, into the central concepts of osteopathic medicine. Indeed, if we believe that the concepts of osteopathic medicine are universal and important, then we must reach out to interpret the data in light of the osteopathic philosophy. No one will do it for us.

MICHAEL M. PATTERSON, PhD

Contributing Editor

\footnotetext{
1. Northup GW: Osteopathic Medicine: An American Reformation, ed 2. Chicago, Ill, American Osteopathic Association, 1979, p 47

2. Korr IM: Proprioceptors and somatic dysfunction. JAOA 1975;74:638650
}

\section{Just what is osteopathic medicine's role in society?}

"What health needs does the osteopathic medical profession purport to meet that are not being met, or likely to be met, by any other profession?"-Irvin M. Korr, $\mathrm{PhD}$

In a recent editorial (JAOA 1990;90:128), I opined that our role in society remains greatly misunderstood, not only by the public, but by many persons in the osteopathic medical profession as well. Osteopathic medicine's boundless potential still remains shackled by a lack of clarity as to its real distinction, its role, and its function in society.

Dr Korr eloquently examines this dilemma in his article, "Osteopathic medicine: The profession's role in society," beginning on page 824. He addresses how we osteopathic physi- cians can use our education skills and philosophy to enhance the prevention of chronic disease in society.

"When osteopathic physicians who are skilled in OMT are also able, themselves or in collaboration with others, to provide guidance for their patients in behavioral, psychosocial, and nutritional realms, they have command of a powerful lever for moving the whole person, and not just a part of the body."

Dr Korr acknowledges, as we osteopathic physicians should, that we have always had the knowledge and skills necessary for maintaining health in our patients: "Having, from its beginning, emphasized in its practice the inherent health-maintaining and the healthrestoring powers, the osteopathic medical profession has long had the opportunity to lead this movement."

I am certain that you, our readers, will agree that Dr Korr's ideas make a seminal contribution to our understanding of the role of osteopathic medicine in addressing society's healthcare needs. The JAOA welcomes and encourages your response and comments.

THOMAS WESLEY ALLEN, DO Editor in Chief

\section{Making the most of growing older}

The aging generation is enjoying a degree of popularity-almost. I have no trouble belonging, for my credentials are more than adequate. Sometimes they are more adequate than others, but adequate nonetheless.

Robert Browning said it well when he wrote:

I'm growing fonder of my staff; I'm growing dimmer in the eyes; I'm growing fainter in my laughs; I'm growing deeper in my sighs; I'm growing careless of my dress;

(continued on page 790) 